\title{
Implications of Some Selected Ethical Theories for Environmental Sustainability and Development in Nigeria
}

\author{
Ephraim Ahamefula Ikegbu ${ }^{1}$, Maduka Enyimba ${ }^{1}$
}

\begin{abstract}
Human actions and conduct have both positive and negative effects on humankind and its environment. This is why ethicists have propounded different theories that are supposed to guide peoples' conduct in order to distinguish the right from the wrong. Environmental ethics as an aspect of environmental philosophy attempts a justification of the rightness and wrongness of human activities as they affect other non-human members of the society or environment. Despite the efforts of both ethicists and environmentalist, humans have continued to conduct themselves in a manner, most unhealthy to the environmental resources. This is the problematic that informed this research on "Ethics, Environment and Philosophy: Towards Sustainable Development in Africa". The main objective is to apply selected ethical theories to the philosophical study of environment in order to ascertain their implications for sustainable development in Africa. To achieve this goal, philosophical methods of critical analysis, conceptual clarification and deduction were employed in the examination and exposition of the nature and tenets of the following selected ethical theories: Platonism, Hedonism, Subjectivism, Teleologism and Deontologism. It was discovered upon application that, these theories present both positive and negative implication for environment, philosophy and development. Hence, humans must be positively minded whenever they undertake any action be it from the perspective of Platonists, Hedonists, Subjectivists, Teleologists or Deontologists. If there must be development and sustainability in the environment, then the positive aspects of each of these theories must be harnessed to yield what this paper describes as environmental eclecticism.
\end{abstract}

Keywords: Ethical Theories, Environment, Philosophy, Sustainable Development, Environmental Eclecticism.

\section{Introduction}

Ethics as a branch of philosophy concerns itself with the study of morality in relation to human conduct in the society and as it affects humans and their fellow and indeed the environment in which they find themselves. This idea of ethics is so broad that it envelops an emerging area of environmental philosophy and axiological studies known as environmental ethics. By environmental ethics it is meant, the justification of the rightness or wrongness of human activities as it affects other non-human members of the society or environment (Elliot,1993,286). In other words, human animals are not the only ones to be worthy of moral consideration, but also other species of animals as well as other forms of life which exist in the environment.

The aim of ethical reflection is then, that I myself shall be good and that the world (environment) shall become good through my action (Bonhoeffe 1955,55). Several theories have been developed by philosophers in the area of ethics as ways or 
approaches to determine what actions or conduct are to be moral or immoral, right or wrong, bad or good. Subsequently, some of these theories shall be examined critically and their implications for environmental sustainability and development shall be exposed.

Thus, the paper begins with a conceptualization of the notion of environmental sustainability and development. It then exposes the nature and basic tenets of the selected ethical theories as well as the new idea of environmental eclecticism. Finally, it demonstrates the implications of these ethical theories for environmental sustainability and development, and shows why and how environmental eclecticism provides a better approach.

\section{Environmental Sustainability and Development}

The concept of environment has been defined "as the surrounding in which a person lives. It involves the circumstances and influences on them and their effects on man”. (Oduora \& Enyimba, 2012, 53). This definition suggests that the environment is simply that which surrounds us. In what seems to be a corroboration of the above view of the environment. Oshita refers to the environment as "all conditions surrounding an individual which are extrinsic to that individual, plant or animal (2001, 21). Similarly, Bellany describes environment as "that which surrounds an individual or a community at any point in its life cycle both physical and cultural surroundings" (2007, 154). One obvious implication of these conceptions of environment is the fact that whatever is outside of man/woman or oneself constitutes the environment. This is why the environment is all things external to us. In other words, "man cannot exist or be understood in isolation from other forms of life and from plant life" (Singh, 2007, 135) in which he is submerged.

To sustain the environment and its constituent elements is to ensure improved growth and maintenance of humans, plants, animals and other forms of life resident on the earth or natural environment. The word "sustainability" is drawn from the word "sustainable" which is in turn gotten from the word "sustain" and this means "to give help or strength to". In other words, to be sustainable or sustainability, is the act or process of giving help or strengthening something, in this case the environment, in other for it not to be weakened, destroyed, depleted or degraded. Literally, sustainability refers to that which can be maintained or kept continuously in goal, from an ecological perspective; Singh describes it as the "conservation of ecological balance by avoiding depletion of natural resource (2007, 136). Accordingly, sustainability is the promotion, protection, preservation and enriching of the environment for the present use and future use (Ikegbu, 2017, Ikegbu \& Oduora, 2016). This can be understood as something which has to do with the longevity of resources, commodity, species, ecosystem, humans, earth, etc. Sustainability includes among other things, a very significant sense of preservation and conservation of existing natural and earth resources as it were, a conscientious effort at protection, restoration and maintenance of the natural environment and wildlife is an effort towards preservation and conservation of the ecosystem. It is in this sense that sustainability is simply described as the "ability to last for a very long time" (Thompson, $2014,9)$, and in this specific context, environmental sustainability means all the efforts to 
ensure that the environment lasts for a very long time. Sustainability is thus, a continuous and progressive process (Enyimba 2019, 3).

"Development" is a very important concept in the study of environment. This is mostly because of its remarkable and enduring effects on the ecosystem. Literally, development represents "the act or instance of growth and advancement" (SINGH, 2007, 136). The growth referred to here can be in the sphere of education, industry, economy. population or the wellbeing of human beings. Whichever aspect of growth is in focus, there is an inextricable link between development and the environment. For instance, the environment to put under unbearable pressure by humans generation of comfort and luxuries. The nation's economic activities geared towards growth and development rests wholly on the fragile foundation of earth's resources. These and many more are issues of great concern for environmental studies. The development of science and technology, indubitably, has brought some light and happiness to mankind, yet it has had and may continue to have adverse effects on the environment, if urgency is not exercised in checkmating its recent trend. The notion of development constitute "a steady and gradual growth or change from a not so good state to a relatively stable and better socioeconomic, political, religious and mental state. In this sense development encompasses every aspect of a nation's life bot human and non-human" (Enyimba. Moral Education $(2005,5)$. We had identified two dimensions of development, namely, structural and individual dimension. Accordingly:

When development takes place in an institution or structures in the society or nation, structural or institutional development is said to have taken place. Moreover, when this development or progressive change is found in an individual member of a state, then it is said to be human or individual development. On a large scale, when there is a development in each of these area at a time in a given society, it is said, that national development has occurred (Enyimba Genuine National Development, 2015,3).

What is obvious from the above is that genuine national development is a combination of progressive change in the case of the structures or institutions, individuals, machineries and other resources or component parts of a nation. This will include the earth's resources and natural resources available in such environment. It is in this sense that one can begin to conceive of the notion of sustainable development of the environment within the context or framework of genuine national development.

The notion of sustainable development was popularized by the 1987 report of the world commission on environment and development chaired by Gro Harlem Brundtland. According to this Commission "sustainable development means meeting the needs of the present without compromising the ability of future generations to meet their own needs". (Cunningham et al, 2007, 28). Ikegbu offering explanation on sustainable development contends thus:

Harmonious complementarity in leadership remains a necessary tool that will navigate environmental consciousness and sustainable development in Nigeria. Harmonious complementarity in this context implies the socio-cultural integration, co-operation and cross fertilization of natural and cross fertilization of natural and gifted ideas by the people within a defined political entity for the purpose of confronting a task that is before them. Under this ideal leadership construction, the collective opinions of the people are sought and the consciousness of sustaining, protecting, preserving and/or 
promoting the environment becomes the collective task of the people; both the leader and the led. (European Journal of Sustainable Development (EJSD), 2017, 141 - 154) Thus, sustainable development implies progress in human wellbeing that can be prolonged or extended over many generations. The problematic at this point is whether sustainable development is possible considering the limitedness of nature's resources and human consistent dependence on nature for survival. How can we establish a balance or an equitable equilibrium or exchange between human and the earth's resources?

One way of responding to the troubling question is to examine critically some of the ethical theories that underline human actions and inactions with respect to determining their rightness, wrongness, goodness or badness, their moral worthiness. We shall then see how these theories apply in determining the moral worth of human conduct viz-a-viz the environment and its constituent elements. The benefits of such exercise is that it provides a legitimate ground, evaluate humans' excesses on the environment and the obvious dangers they present. It further prescribes for humans the possible line of action to take for the benefit of both humans and their environment.

\section{An Exposition of Some Selected Ethical Theories}

\subsection{Ethical Platonism}

The thesis of Platonism as an ethical theory is that "moral evil or vice is caused by ignorance or false knowledge" (FEINBERG and RUSS, 2002,567), Plato's view is based on Socrates' moral dictum that "knowledge is virtue and ignorance is vice". This for him is the case because human's primary moral obligation is for human to make itself the finest specimen of human-hood possible and as such knowledge is the key to and the essence of virtue. Thus for Socrates, man does not deliberately involve himself in evil doing if he has good judgment. No man purposely does wrong and no man willfully chooses what will harm him.

Concerning the source of moral evil, Plato explains that the soul existed "in the world of forms" before entering the human body. It was in its previous existence that it enjoyed basic harmony between its rational and irrational parts with reason being in control. But as the soul left the world of forms to inhabit the human body in the physical world it lost its perfect knowledge and became ignorant as a result of the corruption of the body. Thus the theory of Platonism believes that if men are taught the good life, the virtuous life, the will do no less than to avoid evil so as to attain the virtuous living. Platonism maintains that the quest for knowledge is very important and also that moral goodness could be identified with knowledge. Therefore, knowledge is needed to make humans perfectly good or virtuous, and upon the discovery of knowledge humans will refrain from evil and pursue good or virtuous life.

A critical appraisal of Platonism as an ethical theory reveals the significant role that knowledge and education play in the development of the human person. Following Plato's articulation, this should be evident in the character, action and conduct of a person. The fact that degrees in our citadel of learning are awarded to individuals on the basis of character and learning further justifies Plato's ethical idea. However, the dictum "knowledge is virtue and ignorance is vice" would suggest that whoever commits crime or carries out any evil act shall not be punished or held responsible because he/she is not 
aware or rather he/she is ignorant of the constituent of his/her action(s). This is what Plato implies when he opines that if such a person had adequate knowledge, he would do nothing, but avoid evil. The problem here is that, most of the vices, evil acts and wrong doings in our society today, is carried out by not just knowledgeable people but well trained and educated persons occupying responsible positions of authority. This particular observation makes it difficult to completely go along with Plato's ethical theory. For instance, some humans may well know and understand that stealing is wrong, yet they may still persist in stealing. Some are aware of the harm their action may cause the environment, yet they carry on with such act.

In his theory of universal forms, Plato had it that we do not learn anything; rather we remember what we already know, all the knowledge of forms or universal are already in our minds. This by implication suggests that one does not need to acquire knowledge in order to live a good life, since whatever knowledge he/she is to acquire so as to live rightly, he/she already has it. Hence, no one is ignorant at all in this sense. Thus, Socrates' dictum "knowledge is virtue and ignorance is vice" could be baseless and as such incorrect (Enyimba, Democracy, Politics and Society, 2003, 60).

\subsection{Ethical Hedonism}

Hedonism derives from the Greek word 'hedone' which means pleasure. This theory holds that pleasure alone is the highest good" (Uduigwomen 2006, 25). Ozumba describes it as the moral view that pleasure is intrinsically good. The good is the pleasurable and the pleasurable is the good $(2001,104)$. Epicurus, Endoxus, J. S. Mill and Jeremy Bentham are proponents of this theory. Hedonism is of two strands, namely, psychological and ethical hedonism. For the psychological hedonism the pursuit of pleasure alone and the avoidance of pain are the sole activities of which human beings are capable. In other words, the desire for pleasure is the impetus behind every human action or endeavour. Ethical hedonism on the other hand, holds that pleasure is the virtue worth seeking for itself and all other human actions are means to achieving pleasure. Hence, all actions which lead to pleasure are good and should be pursued. The point to note here is that, pleasurable action are good and must be pursued while painful acts are evil and must be avoided.

One major challenge with hedonism is that there are many acts and choices universally regarded as desirable or approvable but are not pleasurable in any precise sense. A good example is the martyr going to the gallows or the scientist carrying out his experiments (Uduigwomen 2006, 30). It maybe true that whatever is good may sooner or later produce pleasure, but it is not true that whatever brings pleasure is good. A major pitfall of hedonism is its inability to make this distinction.

\subsection{Ethical Subjectivism}

According to James Rachels, ethical subjectivism is a theory which says that, in making moral judgments, people are doing nothing more than expressing their personal desires or feelings $(1993,432)$. David Hume for instance, subscribes to this view when he describes morality as a matter of feeling, not reason. According to this ethical theory, moral judgments merely express the attitude of a person towards a given action. If the judgment is positive or negative, it means the person is in favour or against the said 
action respectively. Hence, moral statements, according to this theory are informative of attitude or feeling of the speaker, not the qualities of the object being evaluated. Ethical subjectivism is akin to ethical relativism. This is so because what may be wrong for a person based on his personal feeling may be right for another based on that other person's personal feelings. Thus, ethical subjectivism is opposed to ethical objectivism. Our individual opinions emotions, orientations and value system influence our sense of moral judgments.

Some criticisms have been leveled against ethical subjectivism. It has been argued that if subjectivism is correct, then it means that all the treaties on normative ethics written by great philosophers, past and present tell us nothing but their personal likes and dislikes. Again, as argued by Popkin and Stroll, ethical subjectivism does not seem to justify the moral notion of "doing one's duty". In daily life one is often faced with issues involving one's duty. Against the view of ethical subjectivists, the notion of "doing one's duty" sometimes involves acting against one's interest or inclinations. For instance, one may desire to smoke cigarette, but it may be his duty as a doctor on duty or a teacher in the classroom or as a traveler in the aircraft to avoid smoking (Popkin and Stroll, 1976, 5253).

\subsection{Ethical Teleologism}

This ethical theory argues that rules are not laid down by God and that there are no universal ethical principles. Instead, actions are to be judged right or wrong on the basis of the result they produce (Kunhiyop 2008,34). Teleologism is an ethical theory which holds that the moral worth or value of any action consists in the tendency it has or is intended to have in producing a good or bad result. It is a futuristic theory in the sense that it considers an act to be praiseworthy if it has the tendency to promote or realize that which is the end, or goal which all human behaviour having moral value must aim at realizing. Aristotelianism which is an ethical theory propounded by Aristotle follows this line of thought. It is teleological in that it holds that every human action has a distinctive "end" to achieve or a function to fulfill. In his Nicomachean Ethics, Aristotle held that every action or pursuit is aimed at some good.

Teleologism also bears the name "consequentialism" (Kunhiyop 2005, 34). Pettit in affirming the synonymous use of Teleologism and consequentialism in moral philosophy opines that the "consequentialist theories are theories of the right, but not with any particular theory of value or of the good" $(1993,230)$. By this, he means that any view that whatever values an individual or instructional agent adopts, the major response to those values is to promote them. For the consequentialists as for the teleologists, the proper way for an agent to respond to any recognized values is to promote them.

\subsection{Ethical Deontologism}

This is variously referred to as non-teleologists or non-consequentialist theory. Deontologism is a name given to any ethical theory that contends that some acts are by their very nature obligatory in themselves, irrespective of any tendency they may have in producing an intrinsically good result. Deontological theory is drawn from the Greek word "deon" which means duty. Unlike teleologism which focuses on the results or consequences of an action in order to determine its rightness or wrongness, 
deontological theory insist "certain actions are inherently right or wrong, regardless of their consequences" (Nancy 1993, 205). In other words, deontologism is based on the idea of duty and obligation. Humans must toe certain line of action which are intrinsically good as a matter of duty or obligation and irrespective of their end. Immanuel Kant and W. D. Ross among others belong to this class.

\subsection{Environmental Eclecticism}

This is a philosophical-cum-environmental attitude that amalgamates the positive aspects of existing ethical theories to form a holistic approach to sustainability and development with respect to humans and their relationship with the non-human aspects of their environment. Environmental eclecticism suggests that no ethical theory or environmental ethic is totally defective when applied to the environment, and as such it makes efforts to identify the effective aspects of such theories. Environmental eclecticism de-emphasizes the negative aspects of a theory and emphasizes the need to harness the positive parts of each ethical theory and bring them to bear on the environment in order to ensure sustainability and development. The idea of environmental eclecticism is presented in this paper as the needed approach to environmental sustainability and development in Nigeria. It is seen as a formidable option and/or pragmatic conscious effort in its holistic sense towards addressing environmental issues in the country which consequently will navigate sustainable development.

\section{Implications of these Ethical Theories on Environment, Sustainability and Development}

Positive and negative implications abound in applying these ethical theories to philosophical, theoretical and practical study of the environment. In other words, how are we to relate with our environment based on the understanding of the foregoing ethical theories so as to ensure sustainable development in the country? In fact, these ethical theories in praxis, have direct and indirect effects on our perception of our environment and for its sustainability.

For instance, an application of the ethics of Platonism would demand wide spread conscientization by means of education through which information and knowledge about the importance of conservation of the environment and other natural resources would be necessary. This is so because following the ethical theory of Platonism, if humans should have adequate knowledge of the need for environmental conservation, they will act in a manner not only to ensure conservation but also sustainability. They would make themselves ready agents and environmental 'torch bearers' for protection, preservation, promotion and conservation of environment for immediate and future benefits.

Again, Platonism as an ethical theory posits that if the human person and by extension the society should have peace and experience virtuous living, then the three parts of both the soul and the society must not only perform their individual duties but must also work harmoniously for the good of the entire system. Thus, the goal of environmental sustainability stands to benefit a great deal such that other creatures of the environment 
outside humans would flourish thereby maintaining a balance in the ecosystem. What is meant here is that with this platonic ethics at the back of humans mind, they will understand that other animals, plants, seas, landscape and other natural resources have a right to exist and a duty to perform in the maintenance of some levels of equanimity in the environment: Indeed, these non-human aspects of the environment need to be recognized and co-operated with if we must have the much desired environmental protection, conservation and sustainability.

In line with Platonism, it is hoped that humans, when armed with the appropriate knowledge will avoid actions that will be detrimental to the environment. On the other hand, any human or citizen caught in any act or abuse of the environment or its elements should be perceived as ignorant and therefore not be punished but educated and reoriented. The problem with this particular direction is that, it condones and indirectly encourages those who deliberately engage in anti-environmental activities with reckless abandon, whilst feigning ignorance.

The problem with Hedonism is the idea of pleasure as the ultimate good while pain is evil. The reason for this assertion is that if this is applied as a moral principle to the investigation of environmental concerns, it will be discovered to be problematic. What humans find pleasurable may not be necessarily good and what may be good in itself may not be pleasurable. The implication here is that, if one finds it pleasurable killing animals and/or destroying aspects of the environment to be judged good in so far as it gives human pleasure. This attitude certainly will not encourage a healthy and preserved ecosystem. Many animals will become endangered and the aesthetic texture of the environment will be marred.

However, if construed from a positive perspective, hedonism would demand that humans should desire pleasure in the existence of different species of animals, trees and plants in a controlled atmosphere. This will create room for relaxation, recreation and the feelings of aesthetic experience. Hedonism when conceived from this perspective and applied to the environment will encourage eco-tourism which in turn will bring foreign exchange to the society. In other words, if we follow Bentham's view of hedonism, we will realize that pleasure and pain are not only human attributes but also affect other sentient beings, so we ought to treat them with this in mind.

Following ethical subjectivism one is entitled to one's views and opinions whether others agree with one or not in so far as such views or acts are not injurious to others and the physical environment. For instance, when one opines that there is no harm or danger in repeated bush burning, or that there is no gain in bothering about pursuing endangered species, such a person makes subjective value judgment. The implication of this for environmental philosophy and for sustainable development is that it allows individuals to express their views or carry out some activities or reasoning as a functional organism (Emeh et al 1995, 106). For instance, the dumping of industrial wastes into rivers in the hope that they will be washed away down the river is a dangerous subjective judgment. The question do other people not live down the river and may make use of water from the same river and are there no other aspects of nature-living and non-living, inhabiting the rivers? It is therefore futile to quarrel with one who puts into action his subjective views on the environment. If the view is wrong and would pose a threat to the ecosystem and retard sustainable development, then we must apply persuasion, empathy, 
education and understanding to convince the person otherwise. Similar problems arise when a community sees no harm in reckless mining or over-grazing which continually degrades the land. Here again, persuasion and education become necessary.

Concerning teleologism or ethical consquentialism, it will lead a person to unspeakable deeds so long as he achieves his selfish end or goal. Thus, if an evil act such as oil spillage, gas flaring, overgrazing, deliberate pollution etc, promise the best consequences for a person, teleologism allows him to carry on with the act, despite its negative effects on the ecosystem and on developmental process.

However, there is the positive impact of teleologism or consequentialist ethical theory for the philosophical study of the environment. It is that, it shows that the universe, the society and indeed the environment have a purpose or an end in view. Hence, humans themselves who are not a being in chance, but also a being with purpose or goal, must align his goals with that of the universe and the environment which they live. With this, there will be balance, harmony preservation and sustenance of ecological system.

Deontological theory which demands that humans act in a prescribed manner as a matter of obligation or duty has some positive implications for the philosophy of environment. By this ethical theory, every individual irrespective of his/her opinion and personal inclination is duty bound to protect, preserve and sustain the environment. Hence, whether they like it or not, individuals must engage in acts that will bring about sustainable development of the environment. It must be noted that the acts which this theory imposes on the individual may not be pleasurable or desirable, but must have intrinsic value or good for the general wellbeing of the society in large and the environment in particular.

\section{Conclusion}

We have attempted in the foregoing pages to expose the negative and positive imports of Platonism, Hedonism, Teleologism and Deontologism as ethical theories. Since each has both negative and positive implication, we propose that a combination of the positive aspects of each theory will present Africa with the right ethical framework that will ensure the conservation and sustainability of the environment and its resources. The reason for this proposal is that Africans, everywhere may behave differently in a given situation or condition. This could be as a result of differences in culture, background, experience, influences etc. It is the opinion of this work that these different cultures, backgrounds and influences have some ethical or moral underpinnings. The point should be noted that cultural differences among people justify their different attributes in relation to the environment. Some are ignorant of the effects of their actions on the environment, whereas some who are aware of the harmful effect of their actions continue to express them. Some persons are care-free and pleasure-driven in their actions and conducts, as they take delight in environmental harmful acts. There are others who are so self-centred that, only actions whose end-result is beneficial to them can be undertaken. Yet others are so dutiful that they see themselves as the custodian of nature and of the environment and these influence their actions and relations with the environment. Hence, a person with a hedonist moral bent would react differently from the one with a Platonist' moral bent in the given circumstance. The same would be the 
case between a teolologist and a deontologist. But what remains clear is that, no matter one's ethical inclination, it has both positive and negative implications for both the environment and the society at large. Based on this, the work maintains that an amalgamation of the positive aspects of these ethical theories would rightly enhance human effort towards conservation and sustenance of the environment and its constituent elements. This is called the "theory of environmental eclecticism" and it is presented here as the right ethical frameworks that will help achieve sustainable development of the virtue of African environment.

\section{References}

Bellany, P. Dictionary of Environment, Delhi: Academic India Publishers, 2007.

Bonghoeffer, Detrich. Ethics. London: SMC Press, 1955.

Cunningham, W. P. Cunningham, M. A. and Saigp, B. W. [Environment Science: A Global Concern]. New York: McGraw-Hill, 2007. Paper Back.

Elliot Robert. "Environmental Ethics"[A Companion on Ethics]. Peter SINGER (ed) UK: Blackwell Publishers, 1993 (254-293). Paper Back.

Emeh, J. U. Ntia, N. U. Usang, E. and Enukoha, O. I. [Philosophical Issues in Environmental Education]. Lagos: Macmillan Publishers, 1995. Paper Back.

Enyimba, Maduka. "Ethics and Development in Nigeria" [Introducing Ethics: Trends and Problems] Uduigwomen, A. F. (ed.) Calabar: Jochrisam, 2006 (234-243). Print.

"Moral Education and Development in Nigeria [International Journal of Research in Arts and Social Sciences] 8(1), 134-141, 2015. Print.

"Towards a Genuine National Development: A Case for Kant's Epistemic Cooperativism in Nigeria" being a paper presented at the conference of the Council for Research in Values and Philosophy held at Ebonyi State University, Abakalili 10-14th June, 2015.

Print.

[Democracy, Politics and Society: A Philosophical Approach] Calabar: Iyke Press, 2003.

Enyimba, M "Sustainable-Inclusive Development Through Conversational Thinking: The Case for AfricaChina Relations" [Filosofia Theoritica: Journal of African Philosophy, Culture and Religion], pp 120, 2019 Vol. 8 No. 1. Print.

Feinberg, T. and Russ, S. [Reasons and Responsibility: Readings in Some Basic Problems of Philosophy]UK: Wordsworth, 2002, Paper Back.

Ikegbu, Ephraim A. "Harmonious Complementarity of Leadership and Environment: A Necessary Tool for Environment and Sustainability" European Journal of Sustainable Development, 6 (3) 2017, 141 154

Ikegbu, Ephraim A and Oduora O. Asuo. "Leadership and Environment for Sustainable Development in Nigeria" Contemporary Journal of Interdisciplinary Studies Vol 5, No 3, 2016346 - 351.

James, Rachels. "Subjectivism" [A Companion to Ethics] Peter, Singer (ed.) U.K. Blackwell, 1993 (432 441) Paper Back.

Kunhiyop, S. W. [African Christian Ethics] Nairobi: Hippo Books. 2008. Print.

Nancy, Davis, S. W. "Contemporary Development" [A Companion to Ethics] Peter, Singer (ed.) U.K. Blackwell, 1993 (205 - 218) Paper Back.

Oduora, Okpokam O. and Enyimba, Maduka [Environmental Philosophy: Concepts, Issues and Perspectives] Lagos: Greymatter, 2012. Print.

Oshita, G. O. [Philosophy, Education and Environment: The Dialectic of Knowledge] Calabar: University of Calabar Press 2001. Print.

Ozumba, G. O. [A Concise Text on Ethics] Lagos: O. O. P, 2001 Print.

Pettit, Philip. "Consequentialism" [A Companiomn to Ethics] Peter Singer (ed) UK: Blackwells, 1993 (230 240). Paper Back.

Popkin, R. and Stroll, A. V. [Philosophy Made Simple]. New York: Allen \& Unwin, 1976/. Print.

Singh, Y. E. [Teaching Environmental Science]. New Delhi: APH Publishing Corporations, 2002. Print. 
Thompson, Lucky O. Environmental Sustainability in the Age of Modernity. An Unpublish B.A. Long Essay Submitted to the Department of Philosophy, University of Calabar, 2014.

Uduigwomen, A. F. [Introducing Ethics: Trends, Problems and Perspective]. Calabar: Jochrisam, 2006. Print. 